\title{
Tube-jack testing: Semi-irregular masonry wall testing
}

\author{
E.C. Manning \& L.F. Ramos \\ ISISE, Department of Civil Engineering, University of Minho, Guimarães, Portugal \\ F.M. Fernandes \\ ISISE, Lusiada University, Vila Nova Famalicão, Portugal
}

\begin{abstract}
Tube-jack testing is an enhanced non-destructive or minimally-destructive testing technique being developed to determine the state of stress in, and the deformability characteristics of, unreinforced masonry. This test is similar to traditional flat-jack testing, used for the same purpose. Instead of using flat-jacks, the tubejack system consists of several cylindrical jacks inserted into roughly aligned holes drilled in the mortar joints, forming an equivalent flat-jack, that can pressurize the masonry. In previous Structural Analysis of Historical Constructions Conferences, the development of this method has been presented. In this paper, testing in a masonry wall with a semi-irregular typology is presented. Two single tube-jack tests were performed to try to determine the level of stress in the masonry and one double tube-jack test was performed to estimate the deformability characteristics of the masonry. These tests are presented along with comparisons to traditional flat-jack tests performed in the same wall.
\end{abstract}

\section{INTRODUCTION}

Tube-jack testing is an enhanced non-destructive or minimally-destructive test method being developed at the University of Minho. The method was first introduced at the 2010 Structural Analysis of Historical Constructions (SAHC) Conference in Shanghai, China (Ramos \& Sharafi, 2010). Development of tubejack prototypes and initial testing was presented at the 2012 SAHC Conference in Wroclaw, Poland (Manning et al. 2012), with additional details included in Ramos et al. (2012). At the 2014 SAHC Conference in Mexico City, Mexico, the first complete single and double tube-jack tests results were presented, showing that the method could be performed in a masonry wall with a regular typology (Manning et al. 2014). This paper presents the next phase in the laboratory testing of the tube-jack test method. In this phase, single and double tube-jack tests were performed in a masonry wall with a semi-irregular typology. This wall was built of the same granite as the masonry wall with a regular typology that was tested in the previous phase. For comparison, single and double flat-jack tests were performed in the same wall under the same laboratory conditions. In the following sections tube-jack test theory, characterization of the materials, test procedure, results, analysis and conclusions will be presented for the tube-jack and flat-jack tests performed.

\section{TUBE-JACK TEST THEORY}

The tube-jack test method is based on the same principals as used in the standards for the single and double flat-jack test (ASTM Standard C 1196-04, 2004) (ASTM Standard C 1197-04, 2004) (RILEM Recommendations MDT.D.4 and MDT.D.5, 2004). However, instead of flat-jacks the tube-jack test uses multiple cylindrical jacks inserted in drilled holes in the mortar of an unreinforced masonry specimen to form equivalent flat-jacks to pressurize the masonry. A single line of tube-jacks can be used as an equivalent single flat-jack to determine the state of stress in the masonry. A double line of tube-jacks can be used to determine the elastic modulus of the masonry and estimate the compressive strength and Poisson ratio of the masonry.

As in the flat-jack test, during the tube-jack test when the pressure applied by the jacks to the masonry, $P_{\text {Applied }}$, is equivalent to the compressive stress state in the masonry, $\sigma_{m}$, the relative displacements caused by creating openings in the masonry are returned to zero. Determining the pressure applied to the masonry, $P_{\text {Applied }}$, involves several calculations. Considering a tube which has an inner radius $a$ and an outer radius $b$, the initial thickness of the tube wall is $t_{i}=b-a$ when no pressures are exerted on the tube. The rubber tubing used for the tube-jacks had an inner radius of $6.34 \mathrm{~mm}$ and a thickness of $0.82 \mathrm{~mm}$. The Young's modulus, $E$, of the rubber tubing material has been tested to be $2.32 \mathrm{MPa}$ with a standard deviation of $0.044 \mathrm{MPa}(\mathrm{COV}=1.91 \%)$ following ASTM standards (ASTM Standard D412, 1998). The Poisson ratio, $v$, is assumed to be 0.499 . The tube is subjected to internal water pressure, $p_{w}$, and external masonry pressure, $p_{m}$, as shown in 4 . Due to these pressures, the tube will deform radially so that the new inner radius is $c$ and the outer radius is $d$. 

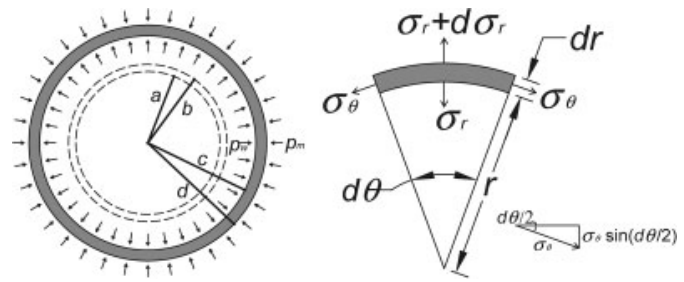

Figure 1. Section of an unstressed tube (dashed) and stressed tube under pressures and small element within the thickness of the rubber tube.

In the deformed tube, the radial pressure through the wall of the tube will vary between $p_{w}$ and $p_{m}$. Consider a small element within the thickness of the tube as shown in 4. This element is located at radius $r$ and has a thickness $d r$ and length $d z$ along the axis of the tube. The radial dimension of the element is $r d \theta$ at radius $r$. Since the pressure varies through the thickness of the tube there is a radial stress $\sigma_{r}$ at radius $r$ on the element. A slightly different stress $\sigma_{r}+d \sigma_{r}$ would act at the other edge of the element at radius $r+d r$. To satisfy equilibrium, the stress difference results in a tangential or hoop stress $\sigma_{\theta}$. By circular symmetry, the stresses $\sigma_{\theta}$ and $\sigma_{r}$ are functions only of $r$. Thus, there are no shear stresses in the tube. Considering equilibrium of forces in the radial direction and performing several mathematical operations, yields the radial and tangential stresses at a radius $r$ within the thickness of the tube. These Equations, Equation 1 and Equation 2, are known as Lamé's equations.

$$
\begin{aligned}
& \sigma_{r}=\frac{p_{m} c^{2}-p_{w} d^{2}}{c^{2}-d^{2}}+\frac{c^{2} d^{2}\left(p_{w}-p_{m}\right)}{c^{2}-d^{2}} \frac{1}{r^{2}} \\
& \sigma_{\theta}=\frac{p_{m} c^{2}-p_{w} d^{2}}{c^{2}-d^{2}}-\frac{c^{2} d^{2}\left(p_{w}-p_{m}\right)}{c^{2}-d^{2}} \frac{1}{r^{2}}
\end{aligned}
$$

The tube-jacks were designed with a bolt inside the tube to resist the longitudinal expansion of the tube. Thus, the axial stress, $\sigma_{z}$, away from the ends of the tube may be assumed as zero. Therefore, Hooke's Law for the tangential stress in the tube becomes:

$\sigma_{\theta}=E \varepsilon_{\theta}+v \sigma_{r}$

Since at radius $r=d$, the exterior of the cylinder, $\sigma_{r}=-p_{m}$, inserting Equation 1 and Equation 2 into Equation 3 and rearranging to solve for the external masonry pressure, $p_{m}$, yields:

$p_{m}=\frac{E \varepsilon_{\theta}\left(c^{2}-d^{2}\right)+2 p_{w} c^{2}}{c^{2}+d^{2}+v\left(c^{2}-d^{2}\right)}$

The tangential strain, $\varepsilon_{\theta}$, at radius $r=d$ depends on the stressed and unstressed circumference of the tube:

$\varepsilon_{\theta}=\frac{2 \pi d-2 \pi b}{2 \pi b}=\frac{2 \pi(d-b)}{2 \pi b}=\frac{d-b}{b}$
The radial strain, $\varepsilon_{r}$, can be determined based on the initial thickness, $t_{i}$, and final thickness, $t_{f}=d-c$, of the tube:

$\varepsilon_{r}=\frac{{ }^{t} f^{-t} i}{{ }_{t}{ }_{i}}=\frac{(d-c)-(b-a)}{(b-a)}$

Inserting Equation 5 and Equation 6 into the equation for the Poisson ratio and rearranging to solve for the inner radius of the deformed tube, $c$, gives:

$c=\frac{v(d-b)(b-a)}{b}+a-b+d$

Equation 7 can be inserted into Equation 4 to determine the external masonry pressure, $p_{m}$. The external masonry pressure on the tube is equal in value and opposite in direction to the pressure the tube applies on the masonry. The water pump applies equal pressure to all of the tube-jacks during the pressurization. The line of tube-jacks forms an "equivalent" flat-jack that applies pressure to the masonry. The calculation of the local state of stress within the masonry can be accomplished with a formula similar to the one used for flat-jack testing (RILEM Recommendation MDT.D.4, 2004.) and (ASTM Standard C 1196-04, 2004), which is presented in Equation 8.

$\sigma_{m}=k_{a} p_{m}$

where: $\sigma_{m}$ is the local state of stress in the masonry, $k_{a}$ is the area correction factor, and $p_{m}$ is the pressure applied to the masonry that is required to return the average relative displacements to zero, i.e., the state before the holes were drilled. Note that in this equation there is no jack calibration factor because the properties of the tube material are taken into consideration in the calculation of the applied pressure. The area correction factor is calculated in the following sections.

\section{WALL CONSTRUCTION AND MATERIAL CHARACTERIZATION}

In this phase of laboratory testing of the tube-jack system, a masonry wall was constructed with a semiirregular typology for the purpose of carrying out the tube-jack and flat-jack tests (see 3.1).

\subsection{Construction}

The same type of granite was used as in the regular masonry wall tested in the previous phase. The maximum size of the units was $20 \mathrm{~cm}$ by $20 \mathrm{~cm}$ by $40 \mathrm{~cm}$ long. The wall was one wythe wide, approximately $20 \mathrm{~cm}$. The cement-lime mortar joints were approximately $3 \mathrm{~cm}$ wide so that the tube-jacks holes could be drilled only in the mortar joints. 


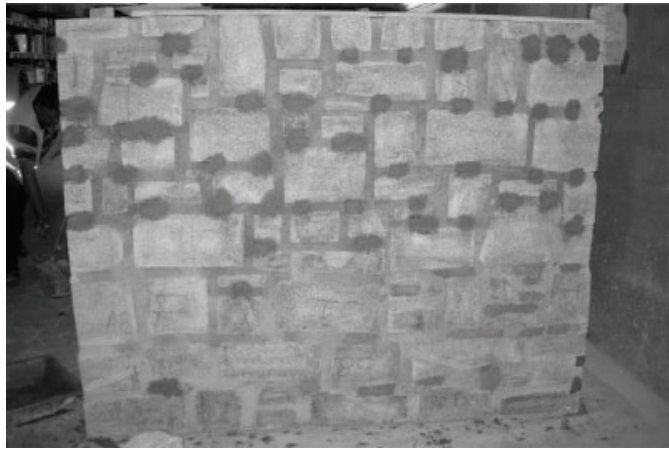

Figure 2. Construction of the semi-irregular masonry wall.

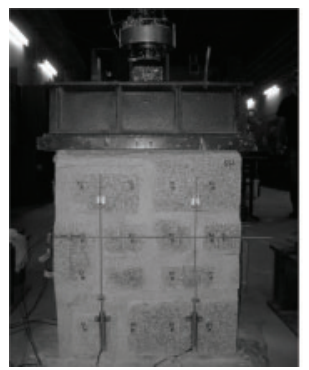

\begin{tabular}{lc} 
Specimen & $\begin{array}{c}\text { ET } \\
{[\mathrm{MPa}]}\end{array}$ \\
\hline SS1 & 690 \\
SS2 & 1279 \\
SS3 & 1042 \\
\hline \hline Average & 1004 \\
Standard Deviation & 296 \\
COV & 30 \\
\hline
\end{tabular}

Figure 3. Setup and results for the small masonry wallet Young's modulus tests.

Three small masonry wallets $60 \mathrm{~cm}$ wide by $70 \mathrm{~cm}$ high by $20 \mathrm{~cm}$ deep were constructed with the same typology and materials.

Mortar cylinders were cast by taking mortar from the batches used for the construction of the wall and wallets. The wall, masonry wallets, and mortar cylinders were cured for more than three months before they were loaded or tested.

\subsection{Material Characterization}

The mortar cylinders were tested to determine their elastic modulus and compressive strength. The test setup and procedure for this test was presented by Manning et al. (2014). The average results are presented in Table 1.

Cyclic compression tests were performed on the three small masonry wallets. Each specimen was loaded and unloaded three times with a maximum load of $250 \mathrm{kN}$, a stress level of approximately $2 \mathrm{MPa}$. The loading and unloading rate was $0.3 \mathrm{kN}$ per second. Linear variable displacement transducers (LVDTs) were used to record the displacement throughout the tests. The test setup followed the European standards for the test (EN 1052-1, 1999). The test set-up and the tangent elastic modulus results, $\mathrm{E}_{T}$, for each of the three specimens are shown in Figure 3.

The stress-strain results for specimen SS3 are shown in Figure 4. These results show how the initial and reloading tangent moduli were determined.

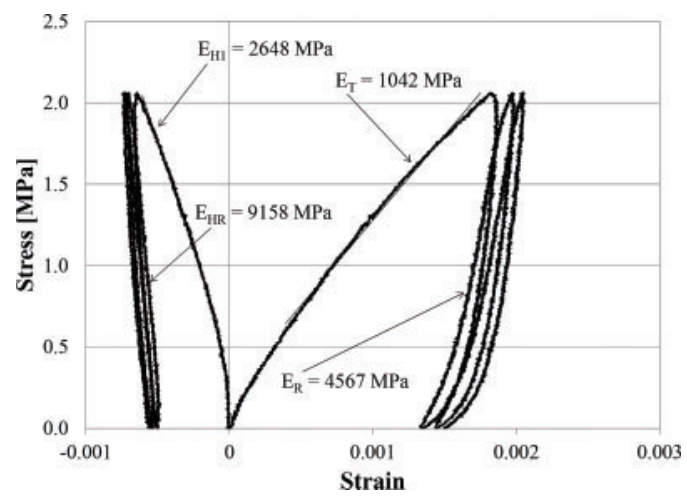

Figure 4. Masonry wallet SS3 test results.

Table 1. Mechanical characterization of the materials results.

\begin{tabular}{|c|c|c|c|c|}
\hline \multirow[b]{2}{*}{ Specimen } & \multicolumn{2}{|c|}{ Young's Modulus } & \multicolumn{2}{|c|}{$\begin{array}{l}\text { Compressive } \\
\text { Strength }\end{array}$} \\
\hline & $\mathrm{GPa}$ & Std dev & $\mathrm{MPa}$ & Std dev \\
\hline Masonry Wallets & 1.004 & 0.296 & $4.17 *$ & - \\
\hline Mortar Cylinders & 0.989 & 0.361 & 3.19 & 0.610 \\
\hline Granite Cylinders & 29.82 & 3.140 & 67.90 & 14.080 \\
\hline
\end{tabular}

* Compressive strength is greater than value shown. Ultimate load could not be reached due to test machine capabilities.

Since the same granite was used for the semiirregular walls as for the regular walls, the granite cylinder tests were not repeated. A full description of the granite cylinder compression and Young's modulus tests can be found elsewhere (Manning et al., 2014). A summary of the results of the characterization tests is shown in Table 1.

\section{SINGLE TUBE-JACK TEST}

A single tube-jack test was performed in the large semi-irregular wall in the laboratory. The following subsections will describe the test set-up, procedure, and results.

\subsection{Set-up and procedure}

The test set-ups for the tube-jack and flat-jack tests were similar. Any differences are noted in each individual test section. The semi-irregular wall was loaded, with two hydraulic jacks and distributed via a steel profile with the same width and length of the wall, the day before each of the tests to a stress of approximately $0.2 \mathrm{MPa}$ within the wall to simulate the loading by floors and additional levels above.

The tube-jack system consists of the set of tubejacks, non-inflatable connection hoses and connection bar, internal water pressure gauge, water pump, 

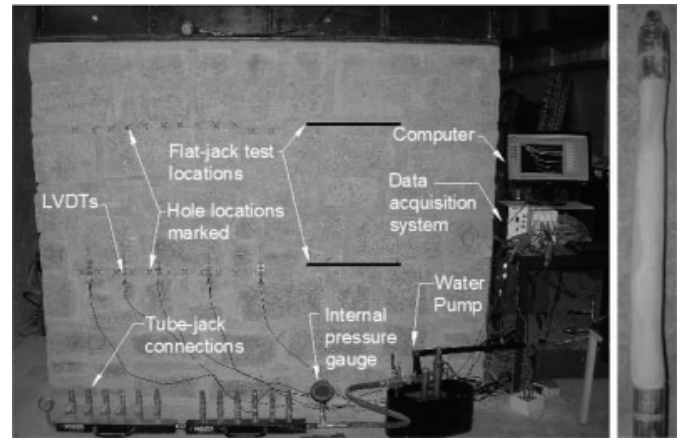

Figure 5. Single tube-jack test set-up and flat-jack test locations shown at left and tube-jack shown at right.
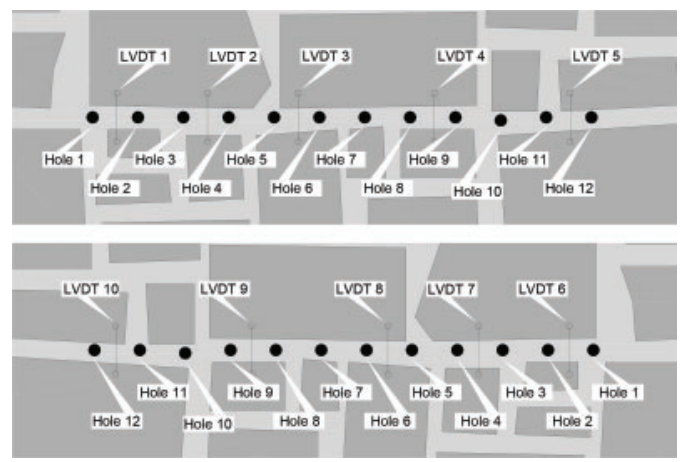

Figure 6. Locations of LVDTs and tube-jack holes - front of the wall shown on top and back of the wall shown on bottom.

LVDTs, data acquisition system, and computer (see Figure 5).

The locations for the holes for the tube-jacks were marked on the mortar joints with a $7.5 \mathrm{~cm}$ center-tocenter spacing. The set of holes create an approximately linear equivalent flat-jack $60 \mathrm{~cm}$ from the base of the wall.

Twelve tube-jacks and ten LVDTs were used for the single tube-jack test. Five LVDTs were positioned on both the front and the back of the wall. The positions and numbering of the holes for the tube-jacks and for the LVDTs are shown in Figure 6.

Once the set-up was complete, the holes were drilled starting from the center holes and working outward. Due to difficulty drilling through the mortar, the drilling process took two and a half hours. In addition, when the drill pushed through to the backside of the wall several larger chunks of mortar were expelled. These chunks were determined to be the fill mortar (seen as dark patches in 3.1) that was placed where wooden blocks were used to hold the units in place during construction.

The LVDTs were able to record the displacement of the wall while the holes were being drilled. However, a couple of the LVDTs were disrupted when the mortar chunks were expelled.
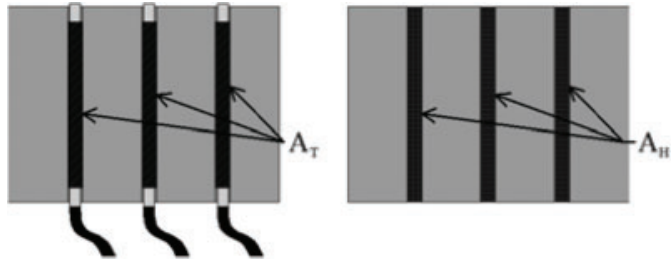

Figure 7. Cross-section of a masonry wall showing area of the holes and area of the tube-jacks.

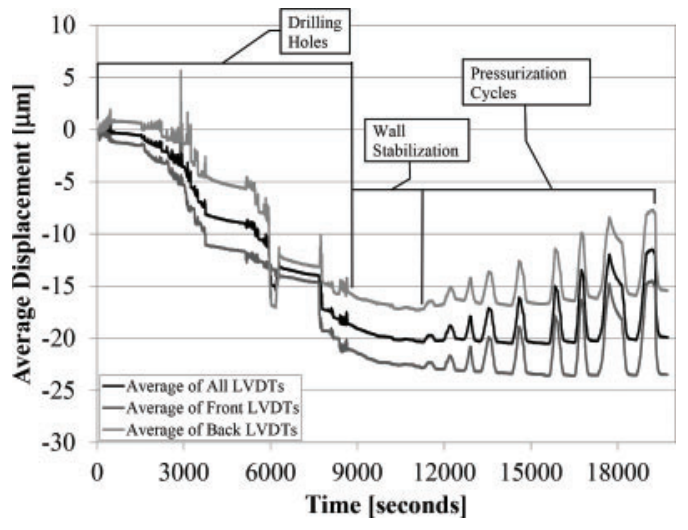

Figure 8. Average LVDT displacement during the single tube-jack test.

The area correction factor, $k_{a}$, was calculated as the ratio of the surface area of the tube-jacks, $\mathrm{A}_{T}$, to the surface area of the holes, $\mathrm{A}_{H}$, in the plane of the equivalent flat-jack (see 4.3). Including the area of the expelled mortar as part of the area of the holes, the area correction factor was calculated to be 0.787 .

The diameter of the holes was estimated to be $26 \mathrm{~mm}$ based on average measurements taken of similar holes made in the previous phase of the work in the regular masonry wall. The hole diameter was used in the calculations of the pressure applied to the masonry by the tube-jacks, $p_{m}$. This pressure, $p_{m}$, was multiplied by $k_{a}$, to obtain the applied pressure, $P_{\text {Applied }}$, shown in the result graphs.

\subsection{Results}

The average displacement of the LVDTs throughout the test is presented in Figure 8. This figure shows the displacement during drilling, time allowed for the wall to stabilize, and pressurization cycles. Note that the average displacement of the LVDTs on the front of the wall was greater than on the back of the wall. There could be two possible reasons for this difference, there could be some eccentricity in the applied load on top of the wall or the drilling could be inducing some bending in the wall.

Ten pressurization cycles were conducted with each subsequent cycle having a greater maximum pressure up to an applied pressure of $0.65 \mathrm{MPa}$. Figure 9 


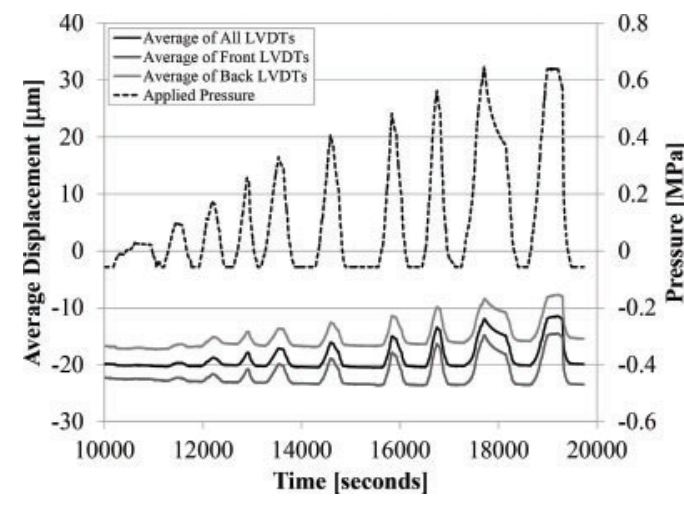

Figure 9. Comparison of average displacement and applied pressure during pressurization cycles.

Applied Pressure [MPa]

$\begin{array}{lllllllllllllllll}0 & 0.1 & 0.2 & 0.3 & 0.4 & 0.5 & 0.6 & 0.7 & 0.8 & 0.9 & 1 & 1.1 & 1.2 & 1.3 & 1.4\end{array}$

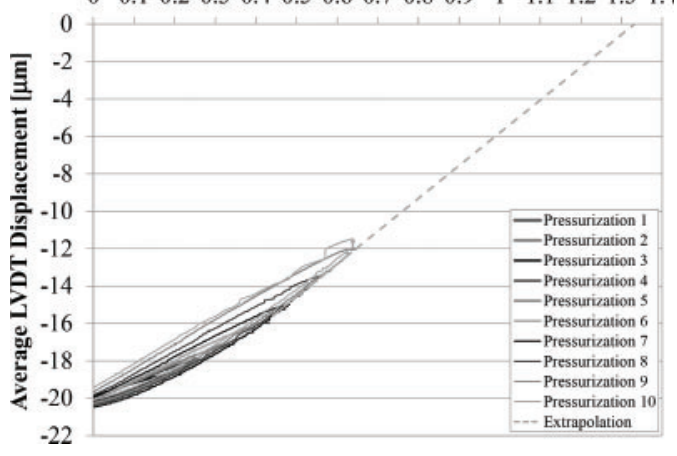

Figure 10. Single tube-jack test calculated pressure versus average LVDT displacement relationship.

shows the average LVDT displacement and the applied pressure during the pressurization cycles.

The average LVDT displacement versus the applied pressure is shown in Figure 10. In this tube-jack test the tube-jacks were not able to reestablish the initial position of the masonry before drilling the holes, see also Figure 9. A linear extrapolation is shown in Figure 10 that estimates what the applied pressure would have to be to restore the masonry to its original position, over 1.3 MPa. This estimate is much higher than the applied vertical stress level of $0.2 \mathrm{MPa}$. Further study must be done to determine the reason for this error.

\section{SINGLE FLAT-JACK TEST}

A single flat-jack test was performed on the right side of the semi-irregular wall at approximately the same height as the single tube-jack test, see Figure 5. The purpose of this test was to compare the tube-jack test to the flat-jack test under the same conditions for both tests.

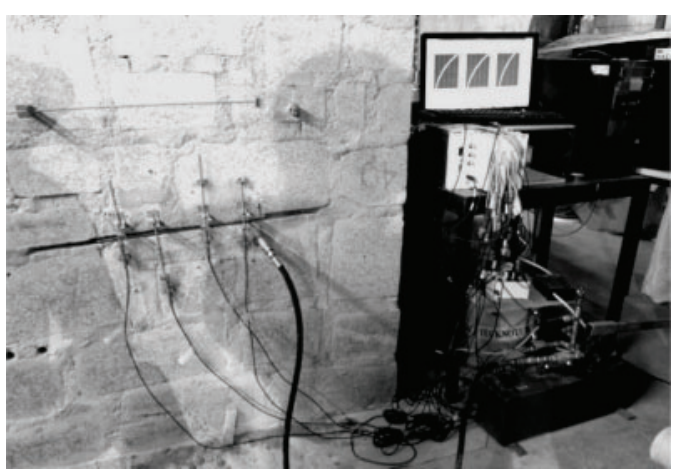

Figure 11. Single flat-jack test set-up.

\subsection{Set-up and procedure}

The single flat-jack test was performed according to standards (ASTM Standard C 1196-04, 2004) and recommendations (RILEM Recommendation MDT.D.4, 2004). A $40.5 \mathrm{~cm}$ long by $10 \mathrm{~cm}$ wide flat-jack was used for the test. This flat-jack had a jack calibration factor of 0.8

Two methods were used to measure the movement of the wall during the test. To determine the displacement of the wall from cutting the slot for the jack, a demountable mechanical strain gauge (DEMEC) was used. Points were glued to the masonry above and below the location of the slot. Several measurements were taken before and after the slot was cut. Once the slot was made and the flat-jack was inserted, LVDTs were attached to the masonry, four LVDTs measuring over the slot on the front of the wall and four on the back of the wall. These LVDTs were connected to a data acquisition system and computer to record the movement of the masonry during the pressurization phase of the test.

The slot was cut using a circular saw. Water was used to reduce the amount of dust and a vacuum was used to suck up additional dust and debris on the other side of the saw. Thus, the cutting required three people as opposed to one person in the case of the tube-jack test. The area correction factor was calculated to be 0.496 . The complete test set-up with the flat-jack inserted in the slot is shown in Figure 11.

\subsection{Results}

The average LVDT displacements on the front and back of the wall and the applied pressure during the two flat-jack pressurizations are shown in Figure 12.

There are a couple of things to note about the presented results. For the flat-jack test, the applied pressure takes into account both the area correction factor and the jack calibration factor. In addition, the LVDT measurements on the front of the wall have been adjusted for the initial relative displacement, measured using the DEMEC points, due to cutting the slot.

The front LVDTs in Figure 12 indicate that the slot is opening during the pressurization of the jack, the back 


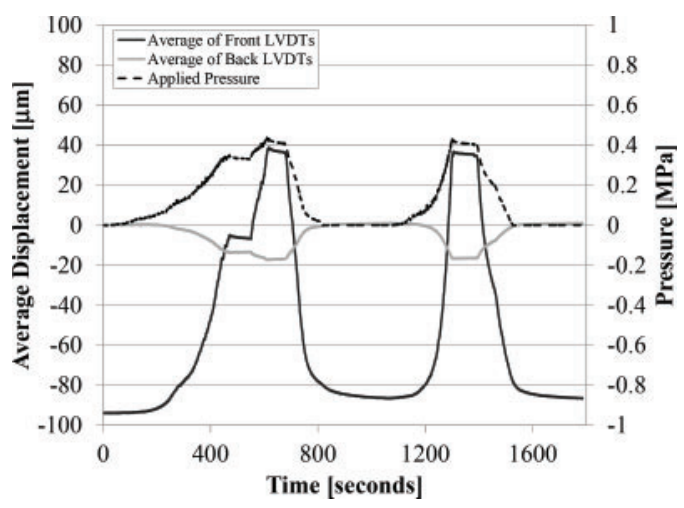

Figure 12. Single flat-jack test results.

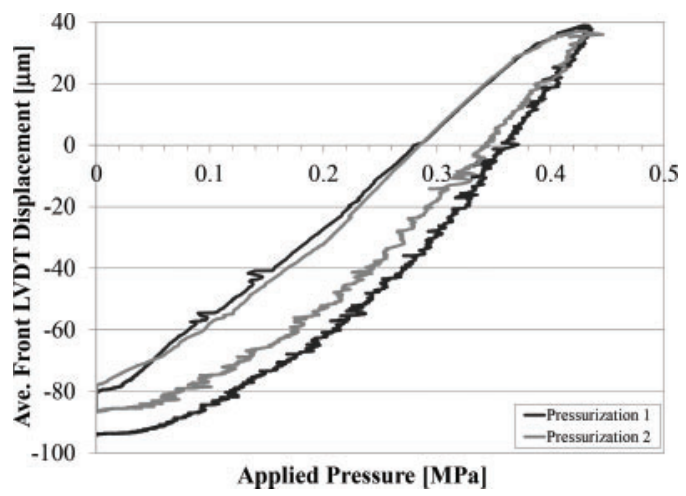

Figure 13. Single flat-jack test pressure versus displacement.

LVDTs are moving in the opposite direction, indicating additional compressive stresses. The relative displacements due to cutting the slot and pressurizing the jack are on a much larger scale than in the tube-jack test.

The graph of pressure versus average front LVDT relative displacement (Figure 13) shows that the flatjack was able to apply enough pressure to return the masonry to its approximate position before the slot was cut.

The applied pressure when the displacement is returned to zero, or the estimated local state of stress, is $0.36 \mathrm{MPa}$. While the estimated local state of stress is closer to the stress level due to the loading on the wall, 0.2 MPa, than in the tube-jack test, the flat-jack test is still over estimating the stress level in the wall.

\section{DOUBLE TUBE-JACK TEST}

A double tube-jack test was performed in the same semi-irregular wall as the single tube-jack test and single flat-jack test. The loading on the wall for this test was the same as for the other tests. The purpose of the double tube-jack test is to estimate the deformability characteristics of the masonry including the Young's modulus and the Poisson ratio.

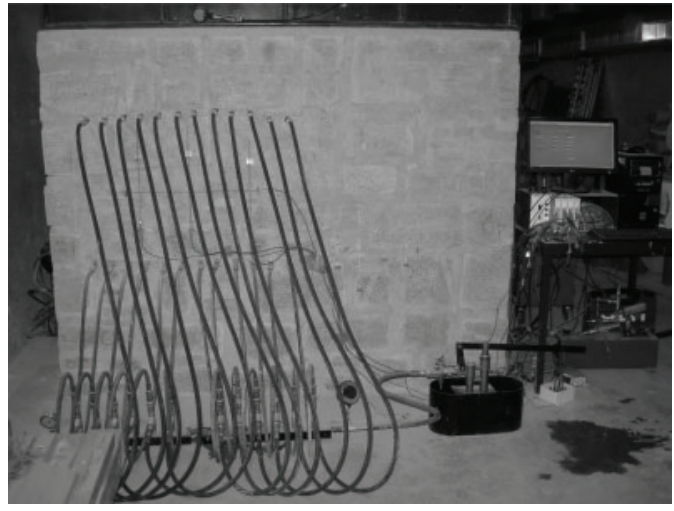

Figure 14. Double tube-jack test set-up.

\subsection{Set-up and procedure}

The double tube-jack test follows a similar set-up and procedure to the standardized double flat-jack test. The locations for a second line of tube-jack holes are marked on a mortar joint above the first line of holes. The drilling of the holes for the second line of tubejacks is performed in a similar way to drilling the first line of holes. The holes are drilled starting in the center of the line and working outward. Once the holes are drilled and the wall has been allowed some time to stabilize, the tube-jacks are inserted into the holes. The tube-jacks are connected to the same connection bar as the tube-jacks from the first line of jacks so that the pressure in the whole system is equal.

Once drilled, this second line of holes becomes a second equivalent flat-jack. The two equivalent flatjacks separate a masonry specimen between them that will be pressurized by the tube-jacks. To record the movement of the masonry between the two lines of tube-jacks, LVDTs are attached to the masonry on the front and back of the wall. The complete set-up for the test is shown in Figure 14.

The area correction factor for the double tube-jack test is equal to the average cross-sectional area of the tube-jacks applying pressure to the separated specimen divided by the cross-sectional area of the separated specimen. For this test, $k_{a}$ was equal to 0.309 .

\subsection{Results}

Five pressurization cycles were performed during the double tube-jack test. During the fifth pressurization one of the tube-jacks burst, ending the test. Unfortunately, there was interference with the LVDTs on the front face of the wall due to another test taking place in the laboratory, so only the results from the LVDTs on the back of the wall from two of the pressurizations are presented here (see Figure 15). The applied pressure shown in this graph is equal to the pressure applied by the tube-jacks to the masonry, $p_{m}$, multiplied by the area correction factor, $k_{a}$.

In Figure 15 it can be seen that the tube-jacks pressurize the masonry consistently in repeatable cycles. 


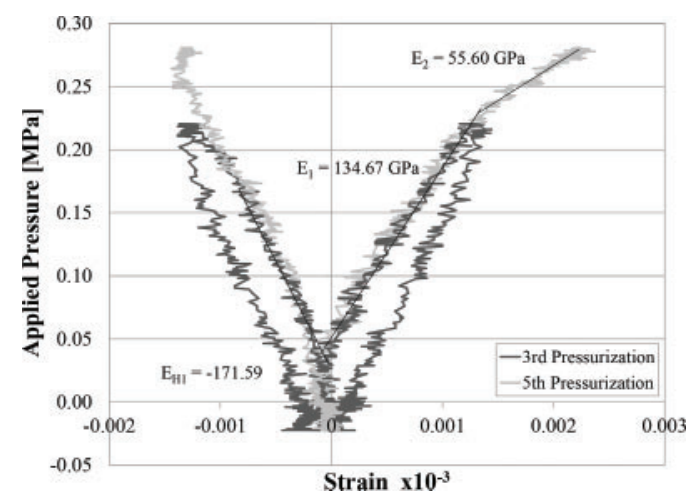

Figure 15. Results of the double tube-jack test.

Note also that the displacements on the back of the wall were very small, resulting in very small strains and high estimates for the Young's modulus. If it had been possible to use the data from the front of the wall, the larger strains shown there could have been incorporated into an average showing a more realistic estimate of the Young's modulus. Even though the Young's modulus estimates shown are not accurate, there is one important observation to make from the graph. There is a definite change in the slope of the stress-strain curve at an applied pressure level of approximately $0.23 \mathrm{MPa}$. While this needs to be confirmed in further testing, this change in slope is likely indicating the maximum level of stress that the masonry has seen.

\section{DOUBLE FLAT-JACK TEST}

A double flat-jack test was conducted in the semiirregular wall just to the right of the double tube-jack test. The purpose of this test was to compare it to the double tube-jack test.

\subsection{Set-up and procedure}

The double flat-jack test used the same flat-jack and slot that was used in the single flat-jack test for the bottom flat-jack. The second slot was cut using the same circular saw as was used for the first slot. Because the mortar joint was not long enough, one of the granite blocks was cut into. In an historic structure, this would have damaged an irreplaceable masonry unit. The total area correction factor for the double flatjack test was calculated to be 0.496 . A flat-jack with the same dimensions as the first flat-jack and jack calibration factor of 0.77 was inserted into the second slot and connected to the oil pump. The jack calibration factors were averaged to obtain the total jack calibration factor of 0.785

To record the displacement of the masonry during the pressurization cycles, LVDTs were attached to the masonry on the front and back of the wall. The locations for the LVDTs followed the standards

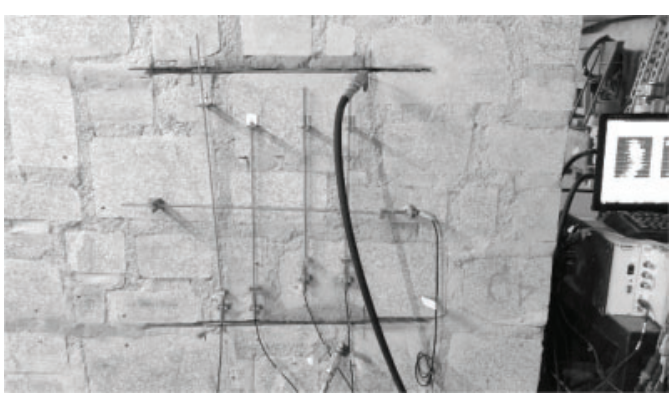

Figure 16. Double flat-jack test set-up.

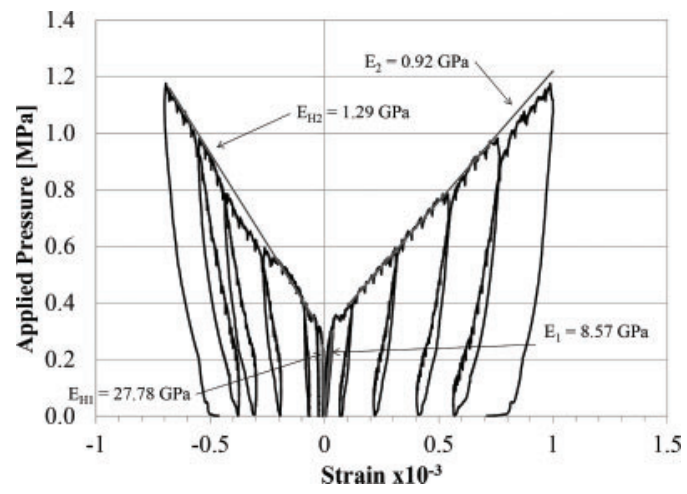

Figure 17. Double flat-jack test results.

and recommendations. The complete set-up for the double flat-jack test is shown in Figure 16.

\subsection{Results}

The results of the double flat-jack test are presented in 8 . The applied pressure is equal to the oil pressure multiplied by $k_{a}$ and $k_{m}$. Several pressurization cycles were conducted, one right after the other with increasing maximum pressures until cracks were observed, with no time for the wall to stabilize in between cycles. Estimates were made for the moduli with tangent trend lines. The initial slope of the average vertical LVDTs was more than ten times higher than the Young's modulus value presented for the small masonry wallets. The second slope for the average vertical LVDTs, $E_{2}$, is closer to the value found for the masonry wallets. It is likely that the confinement of the masonry in the double flat-jack test is causing higher stiffness results than those shown in the masonry wallet tests. The Poisson ratio can be estimated to be 0.31 using the initial slopes for the vertical and horizontal LVDTs.

Comparing the double flat-jack test results with the double tube-jack test results, the maximum pressure applied by the tube-jack test is less than $0.28 \mathrm{MPa}$, whereas the flat-jack test applies nearly 1.2 MPa. The strain in the flat-jack test is almost 500 times larger than in the tube-jack test. The tube-jack test focusing on the initial slope and the flat-jack test focusing 
on the second slope of the stress-strain curve. However, neither test produced the same results as the small masonry wallet tests.

\section{CONCLUSIONS}

In conclusion, a single tube-jack test and a double tubejack test were performed on a masonry wall with a semi-irregular typology for the first time. The discreet nature of the single tube-jack test allowed the displacement of the wall to be recorded through-out the test with only one measurement method. While the tubejacks were not able to pressurize the wall enough to bring it back to its original position, they were able to apply consistent pressurization cycles, showing the test is repeatable. The single flat-jack test was able to recover the displacement that occurred from the slot cutting but the estimated stress was not equivalent to that applied on the wall.

In the double tube-jack test, the placement of the tube-jacks holes could be solely in the mortar joints even though the joint was not exactly level. On the other hand, in the double flat-jack test, the saw had to cut into one of the granite blocks to make the slot for the second jack. The results of the double jack tests showed that the tube-jack test focused on the initial slope of the stress-strain curve whereas the flat-jack was more adequate for observing the secondary slope.

\section{ACKNOWLEDGEMENTS}

The authors would like to acknowledge the Fundação para a Ciência e Tecnologia, which supported this research work as a part of the Project "Improved and innovative techniques for the diagnosis and monitoring of historical masonry", PTDC/ECM/104045/2008. The authors would also like to thank Cláudia Almeida for her help with performing the tests.

\section{REFERENCES}

EN 1052-1. (1999). Methods of test for masonry - Part 1: Determination of compressive strength.

Manning, E., Ramos, L., \& Fernandes, F. (2014). Direct Sonic and Ultrasonic Wave Velocity in Masonry under Compressive Stress. 9th International Masonry Conference. Guimaraes, Portugal.

Manning, E., Ramos, L., \& Fernandes, F. (2014). TubeJack Testing: Regular Masonry Wall Testing. 9th International Conference on Structural Analysis of Historical Constructions. Mexico City, Mexico.

Manning, E., Ramos, L., Fernandes, F., Sousa, C., \& Azenha, M. (2012). Tube-Jack Testing for Irregular Masonry: Preliminary Testing. 8th International Conference on Structural Analysis of Historical Constructions. Wroclaw, Poland.

Ramos, L., \& Sharafi, Z. (2010). Tube-jack Testing for Irregular Masonry Walls: First Studies. Advanced Materials Research, 133-134, 229-234.

Ramos, L., Manning, E., Fernandes, F., Fangueiro, R., Azenha, M., Cruz, J., et al. (2012). Tube jack testing for irregular masonry walls: prototype development and testing. NDT\&E.

RILEM Recommendation MDT.D.4: In-situ stress tests based on the flat-jack, 2004. (n.d.).

RILEM Recommendation MDT.D.5: In-situ stress-strain behavior tests based on the flat-jack, 2004. (n.d.).

Standard Test Method for In Situ Compressive Stress within Solid Unit Masonry, Estimated Using Flat-jack Measurements, ASTM Standard C 1196-04, 2004. (n.d.).

Standard Test Method for In Situ Measurement of Masonry Deformability Properties, Using the Flat-jack Method, ASTM Standard C 1197-04, 2004. (n.d.). 